\author{
Sharon Farnel \\ University of Alberta, Edmonton, Alberta, Canada
}

\title{
METADATA AS DATA: EXPLORING ETHICAL METADATA SHARING AND ACCESS FOR INDIGENOUS RESOURCES THROUGH OCAP PRINCIPLES (Paper)
}

\begin{abstract}
Metadata is often defined as "data about data", and although practitioners and scholars often broaden that definition, there may be value in approaching metadata as a type of data when addressing questions of ethical sharing and access. In this conceptual paper I review the challenges of ethical metadata practice for Indigenous resources, and explore the potential of the OCAP: Ownership, Control, Access, and Possession framework to act as a common language that Indigenous communities and metadata scholars and practitioners can use to engage in meaningful conversations about ethical metadata access and sharing.
\end{abstract}

\section{Metadata as Data}

Metadata in its literal definition is "data about data" (Baca, 2016). This precise definition reflects the origins of the term in communities that deal with the management of geospatial, statistical, or research data (Baca, 2016). Practitioners and scholars within library and information science, however, often expand this definition to capture the richness of the concept. Definitions such as the one proposed by the National Information Standards Organization - "structured information that describes, explains, locates, or otherwise makes it easier to retrieve, use, or manage an information resource" $(2004,1)$ not only broaden the scope of resources metadata can be associated with to include texts, archives, audio or video recordings, images, etc., but also convey the range of functions that metadata can support, such as preservation, management, discovery, etc. Yet this does not negate the possibility of viewing metadata a type of data, for it exhibits many similar characteristics. That is, much like data it can be created and gathered, shared, manipulated and transformed, interrogated, and visualized. And as is the case with data, metadata's power to reveal a great deal about that which it describes (Tasker, 2016), and its power to do harm or good (Olson, 2002) are certainly recognized. Approaching metadata as a type of data affords us opportunities for interrogating research and practice around it, including questions of ethical sharing and access. 


\section{Metadata Ethics and Indigenous Resources}

Information ethics, the application of ethical principles to all aspects of information work (Brody, 2002), emerged within the library and information science literature in the late 1980s (Samek, 2007). Its principles inform all areas of the discipline, including the design, use, and sharing of metadata. This movement incorporates another which had arisen in the late 1960s, which was the growing recognition of the subjective nature of metadata practice. The important role played by context and culture (Alemu \& Stevens, 2015; Mai, 2013; Srinivasan, 2017), the biases inherent in many of the widely adopted metadata tools (Bowker \& Starr, 1999; Olson, 1998, 2002), and the ability of metadata to reinforce power imbalances and perpetuate structural problems such as sexism, racism, and colonialism (Drabinski, 2013; Furner, 2007; Olson, 1999; Yeh, 1971) are now well documented and for the most part accepted within the discipline. While these issues have been highlighted and many have worked to address them, "the fact that some of these structures remain unchanged also reveals important information about the embeddedness of those discourses" (Adler, 2016, p. 631).

Indigenous communities have been particularly negatively affected by the colonial biases inherent in the ways in which established metadata practices have treated resources created by, for, and about them (Berman, 1995, 2000; Duarte \& Belarde-Lewis, 2015; Yeh, 1971). Scholars and practitioners within libraries, archives, and museums have recognized the development of more culturally appropriate metadata as an important component of broader efforts to engage more thoughtfully, respectfully, and meaningfully with Indigenous communities. Efforts towards addressing this have focused largely on greater use of local languages within metadata (Bow, Christie, \& Devlin, 2015; Rigby, 2015), development and application of alternative or revised subject headings or classification notations (Bone, 2016; Littletree \& Metoyer, 2015), and more substantial involvement of local communities in metadata creation (Cedar Face \& Hollens, 2004; Lougheed, Moran, \& Callison, 2015).

These discussions also include themes of access and rights. Indigenous scholars and practitioners remind us that "Indigenous peoples hold collective rights and interests in their knowledge, ... and that the issues surrounding ownership and therefore protection are quite different from those inscribed in Western institutions" (Nakata, 2002, p. 283). In response to this, some within library and information science (Christen, 2007, 2015; Hennessy, 2009) advocate for the use of community protocols to define and control appropriate access. And while these discussions normally focus on the resources rather than on the metadata associated with them, several scholars (Christen, 2017; Godbold, 2009; Littletree, 2018; Nevile \& Lissonnet, 2006) have expressed concern over applying our western library values of broad and open metadata interoperability and sharing, epitomized in OCLC's tag line "what is known must be shared", to metadata associated with Indigenous resources. While these concerns about metadata sharing and 
access have been raised, they have yet to be examined in a systematic way. Approaching these issues from an understanding of metadata as a type of data may afford opportunities for applying specific frameworks for sharing and access, such as OCAP, that come from within the data management community.

\section{OCAP: Ownership, Control, Access, Possession}

OCAP, or Ownership, Control, Access, and Possession, is a "set of standards that establish important ground rules for how First Nations data can be collected, protected, used or shared" (First Nations Information Governance Centre, n.d.). The principles are designed to ensure that Indigenous communities own, protect, and control how data about them is used (First Nations Information Governance Centre, n.d.). Ownership reflects the principle that the community collectively owns its data; control reflects the principle that communities have the right to control all aspects of data management that impact them; access reflects the principle that communities must have the right to access data about them regardless of where that data is held; and possession reflects concrete, physical control of the data, and is a means by which ownership can be asserted and protected. OCAP has been endorsed by Indigenous communities and organizations across Canada, has been integrated into numerous projects (First Nations Information Governance Centre, 2014a; McMahon, LaHache, \& Whiteduck, 2015; First Nations Information Governance Centre, 2014b), and incorporated into guidelines and protocols for ethical research with Indigenous communities (Canadian Institutes of Health Research, Natural Sciences and Engineering Research Council of Canada, Social Sciences and Humanities Research Council of Canada, 2014; Inuit Tapiriit Kanatami, 2018). It is a set of protocols for ensuring appropriate access and sharing of data by and about Indigenous communities.

\section{Approaching Metadata Through the OCAP Framework}

Approaching metadata as a particular type of data and using frameworks that originate from within data management communities can provide opportunities for examining issues of ethical sharing and access within metadata practice and research. Specifically, it can aid us in addressing the following questions:

a) can approaching metadata as a type of data enhance our understanding of issues of ethical sharing and access?

b) can the OCAP framework provide a common language which metadata scholars, practitioners, and Indigenous communities can use to engage in meaningful conversations about appropriate metadata sharing and access? 


\subsection{Metadata as Data}

The practice of metadata sharing has a long history in the library domain. Open and free exchange of metadata is seen as having many benefits for individual organizations as well as the community as a whole, including efficiencies and cost savings through reduction of duplicate work and sharing of expertise, improved quality through collaborative correction and enhancement of records, and enhanced discovery of library resources through aggregator platforms. The importance placed on sharing is evidenced not only by library efforts to ensure that their metadata is openly licensed (British Library, n. d.; DPLA, n. d.; NYPL, 2013), but also by the furor among the community over efforts to hinder sharing, such as that attempted by OCLC in 2008 (Bérard, 2011).

While this imperative is a noble one, in some contexts a more nuanced approach to metadata sharing may be more appropriate. In particular, as libraries increasingly work in collaboration with Indigenous individuals and communities to update and correct deficiencies in descriptions and descriptive practices, or to develop community driven cultural repositories, issues around appropriate and ethical sharing of metadata should be recognized and addressed. In approaching this conversation, it can be beneficial to look to other communities where sharing is common practice, with the research domain being one of the most important.

Data sharing is a foundational norm in many disciplines, and increased emphasis on data sharing by funding agencies and publishers is encouraging all disciplines to make it a priority. Yet there is also a common understanding of "sensitive" data, that is, data that should not by default be openly shared because it contains personally identifying information, community traditional or local knowledge, or information that could potentially cause harm to individuals or communities. Policies and protocols (Canadian Institutes of Health Research, Natural Sciences and Engineering Research Council of Canada, Social Sciences and Humanities Research Council of Canada, 2014; Polar Knowledge Canada, 2017; University of Alberta, 2013) require researchers to think through the data sharing processes, to weigh the benefits and the risks, and to take appropriate measures to mitigate those risks. Looking to such community best practices can encourage metadata practitioners to approach ethical metadata sharing in a similarly systematic way.

\subsection{Metadata as Data and OCAP}

If we consider metadata as a form of data for the purposes of engaging Indigenous communities and metadata researchers and practitioners in meaningful discussions around questions of appropriate and ethical metadata sharing, the OCAP framework can play two critical roles within these discussions. First and foremost, OCAP was developed by First Nations communities for 
First Nations communities. It reflects a worldview in which all knowledge is connected, and in which communities rather than individuals hold rights and interests in their information and data. It recognizes and respects that ownership, control, access, and possession of information and data are critical to self-determination of Indigenous communities and to the maintenance and development of their languages, cultures, and histories.

Secondly, the use of OCAP as a framework for approaching discussions on appropriate and ethical metadata sharing ensures that all individuals and communities involved have a common language with which to express their interests and concerns. It allows for a shared understanding of the concepts of data and information, and creates a safe space for discussion of the problematic history of First Nations and those who have collected or created data by, from, on, or about them. The OCAP framework allows discussions to proceed in the spirit of true collaboration and partnership with a shared commitment to "use and share information in a way that maximizes the benefit to a community, while minimizing harm" (First Nations Information Governance Centre, 2014a, p. 5).

\section{Reference List:}

Adler, M. (2016). The case for taxonomic reparations. Knowledge Organization, 43(8), 630-640.

Alemu, G., Stevens, B. (2015). The Web 2.0 paradigm and the emergence of socially-constructed metadata approaches. In An Emergent Theory of Digital Library Metadata: Enrich then Filter (29-42). Waltham, MA: Chandos Publishing.

Baca, M. (2016). Introduction. In M. Baca (Ed.), Introduction to Metadata. Los Angeles, CA: Getty Research Institute. Retrieved from http://www.getty.edu/publications/introtometadata

Bérard, R. (2011). Free Library Data? Liber Quarterly, 20(3/4), 321-331.

Berman, S. (1995). When the subject is Indian. American Indian Libraries Newsletter, 18(2). Retrieved from http://www.nativeculturelinks.com/ailanewsW95_LCindians.html

Berman, S. (2000). Finding material on "those people" (and their concerns) in library catalogs. MultiCultural Review, 9(2), 28-49.

Bone, C. (2016). Modifications to the Library of Congress Subject Headings for use by Manitoba archives. Paper presented at IFLA World Library and Information Congress. Columbus, OH, August, 2016. Retrieved from http://library.ifla.org/1328/ 
Bow, C., Christie, M., Devlin, B. (2015). Shoehorning complex metadata in the Living Archive of Aboriginal languages. In A. Harris, N. Thieberger, L. Barwick (Eds.), Research, Records and Responsibility: Ten Years of PARADISEC (115-131). Sydney: Sydney University Press.

Bowker, G. C., Starr, S. L. (1999). Sorting Things Out: Classification and Its Consequences. Boston, MA: MIT Press.

British Library. (n. d.). Free Data Services. Retrieved from http://www.bl.uk/bibliographic/datafree.html

Brody, R. (2002). Information ethics in the design, creation and use of metadata. In Social Implications of Information and Communication Technology: Proceedings of the 2002 IEEE International Symposium on Technology and Society (197-201). Piscataway, NJ: IEEE.

Canadian Institutes of Health Research, Natural Sciences and Engineering Research Council of Canada, Social Sciences and Humanities Research Council of Canada. (2014). Ethical Conduct for Research Involving Humans. Retrieved from http://www.pre.ethics.gc.ca/pdf/eng/tcps2-2014/TCPS_2_FINAL_Web.pdf

Cedar Face, M. J., Hollens, D. (2004). A digital library to serve a region: The Bioregion and First Nations collections of the Southern Oregon Digital Archives. Reference \& User Services Quarterly, 2, 116-121.

Christen, K. (2007). The politics of search: Archival accountability in Aboriginal Australia. MIT5: Media in Transition 5 Conference: Technological Translations and Digital Dilemmas Panel. Retrieved from http://web.mit.edu/comm-forum/mit5/papers/Christen.pdf

Christen, K. (2015). Tribal archives, traditional knowledge, and local contexts: Why the "s" matters. Archaeological Record, 8(2), 21-24.

Christen, K. (2017, July 13). We have never been neutral: Search, discovery and the politics of access [video file]. Retrieved from http://www.oclc.org/research/events/2017/07-13.html

DPLA. (n. d.). The Digital Public Library of America Policy Statement on Metadata. Retrieved from https://pro.dp.la/hubs/metadata-application-profile

Drabinski, E. (2013). Queering the catalog: Queer theory and the politics of correction. Library Quarterly, 83, 94-111. 
Duarte, M. E., Belarde-Lewis, M. (2015). Imagining: Creating spaces for Indigenous ontologies. Cataloging \& Classification Quarterly, 53(5/6), 677-702.

First Nations Information Governance Centre. (n.d.). Understanding the First Nations Principles of OCAP. Ottawa, ON: The First Nations Information Governance Centre.

First Nations Information Governance Centre. (2014a). Ownership, Control, Access and Possession (OCAP): The Path to First Nations Information Governance. Ottawa, ON: The First Nations Information Governance Centre.

First Nations Information Governance Centre. (2014b). Barriers and levers for the implementation of OCAP. The International Indigenous Policy Journal, 5(2), 1-11.

Furner, J. (2007). Dewey deracialized: A critical race-theoretic perspective. Knowledge Organization, 34(3), 144-168.

Godbold, N. (2009). User-centred design vs. "good" database design principles: A case study creating knowledge repositories for Indigenous Australians. Australian Academic \& Research Libraries, 40(2), 116-131.

Hennessy, K. (2009). Virtual repatriation and digital cultural heritage: The ethics of managing online collections. Anthropology News, 50(4), 5-6.

Inuit Tapiriit Kanatami. (2018). National Inuit Strategy on Research. Ottawa, ON: Inuit Tapiriit Kanatami. Retrieved from https://itk.ca/wp-content/uploads/2018/03/National-Inuit-Strategy-on-Research.pdf

Littletree, S. (2018). Relationality and Indigenous systems of Knowledge: At the heart of an LIS pedagogy. SLAIS Colloquium, University of British Columbia, 25 January.

Littletree, S., Metoyer, C. A. (2015). Knowledge organization from an Indigenous perspective: The Mashantucket Pequot Thesaurus of American Indian Terminology project. Cataloging \& Classification Quarterly, 53(5/6), 640-657.

Lougheed, B., Moran, R., Callison, C. (2015). Reconciliation through description: Using metadata to realize the vision of the National research Centre for Truth and Reconciliation. Classification Quarterly, 53(5/6), 596-614. 
Mai, J.-E. (2013). Ethics, values and morality in contemporary library classifications. Knowledge Organization, 40(4), 242-253.

McMahon, R., LaHache, T., Whiteduck, T. (2015). Digital data management as Indigenous resurgence in Kahnawà:ke. The International Indigenous Policy Journal, 6(3), 1-19.

Nakata, M. (2002). Indigenous knowledge and the cultural interface: Underlying issues at the intersection of knowledge and information systems. IFLA Journal, 28(5/6), 281-291.

National Information Standards Organization. (2004). Understanding Metadata. Bethesda, MD: NISO Press. Retrieved from http://www.niso.org/publications/press/UnderstandingMetadata.pdf

Nevile, L., Lissonnet, S. (2006). Dublin Core and museum information: Metadata as cultural heritage data. International Journal of Metadata, Semantics and Ontologies, 1(3), 198-206. NYPL. (2013). NYPL Policy on Open Bibliographic Metadata. Retrieved from https:/www.nypl.org/help/about-nypl/legal-notices/open-metadata

Olson, H. A. (1998). Mapping beyond Dewey's boundaries: Constructing classificatory space for marginalized knowledge domains. Library Trends, 47(2), 233-254.

Olson, H. A. (1999). Cultural discourses of classification: Indigenous alternatives to the tradition of Aristotle, Durkheim and Foucault. Advances in Classification Research Online, 10(1), 107-124.

Olson., H. A. (2002). The Power to Name: Locating the Limits of Subject Representation in Libraries. Dordrecht, The Netherlands: Kluwer.

Polar Knowledge Canada. (2017). Data Management Principles and Guidelines for Polar Research and Monitoring in Canada, May 2017. Retrieved from https://www.canada.ca/en/polar-knowledge/publications/data-management-principles-and-guidel ines-2017-may.html

Rigby, C. (2015). Nunavut Libraries Online establish Inuit language bibliographic cataloging standards: Promoting Indigenous language using a commercial ILS. Classification Quarterly, 53(5/6), 615-639.

Samek, T. (2007). Librarianship and Human Rights: A Twenty-first Century Guide. Oxford: Chandos Publishing. 
Srinivasan, R. (2017). Whose Global Village? Rethinking How Technology Shapes Our World. New York: New York University Press.

Tasker, J. P. (2016, November 4). What you need to know about the CSIS metadata ruling: Metadata 'is not an innocuous kernel of information,' judge says. CBC News. Retrieved from http://www.cbc.ca/beta/news/politics/what-you-need-to-know-about-csis-metadata-1.3837104

University of Alberta. (2013). Research Records Stewardship Guidance Procedure. Retrieved from

https://policiesonline.ualberta.ca/PoliciesProcedures/Procedures/Research-Records-StewardshipGuidance-Procedure.pdf

Yeh, T. Y-R. (1971). The treatment of the American Indian in the Library of Congress E-F schedule. Library Resources \& Technical Services, 15(2), 122-128. 